\section{A emergência da Aids no Amazonas}

\section{The emergence of Aids in Amazonas}

Michele Rocha Kadri

Pesquisadora, Instituto Leônidas e Maria Deane/Fiocruz Amazônia. Rua Teresina, 476

69057-070 - Manaus - AM - Brasil

michele.kadri@gmail.com

\section{Júlio César Schweickardt}

Pesquisador, Instituto Leônidas e Maria Deane/Fiocruz Amazônia. Rua Teresina, 476

69057-070 - Manaus - AM - Brasil

juliocesar@amazonia.fiocruz.br

Recebido para publicação em novembro de 2013.

Aprovado para publicação em maio de 2014.
KADRI, Michele Rocha;

SCHWEICKARDT, Júlio César.

A emergência da Aids no Amazonas.

História, Ciências, Saúde - Manguinhos, Rio de Janeiro, v.23, n.2, abr.-jun. 2016, p.301-319.

\section{Resumo}

O artigo analisa o contexto histórico, social e político do surgimento da Aids no Amazonas e como as respostas locais foram moldadas pelas mudanças ocorridas na política nacional. Para isso, utilizou-se pesquisa de fontes documentais - de instituições governamentais e não governamentais complementadas e esclarecidas por fonte oral - relatos de gestores/profissionais de saúde que lideraram a organização da assistência aos soropositivos no estado e ativistas. A partir desse levantamento revelou-se que a desarticulação entre as instituições de assistência e cuidado e principalmente a falta de priorização política para combate à epidemia no Amazonas têm dificultado o planejamento e execução de ações e estratégias públicas com abrangência em toda a rede de assistência no estado.

Palavras-chave: políticas de saúde; Aids; história da saúde; Amazônia.

\section{Abstract}

This article analyzes the historical, social, and political context in which Aids emerged in the Brazilian state of Amazonas, and how local responses were shaped by changes taking place on a national political level. Documental sources from governmental and non-governmental institutions were researched, and the information was supplemented and clarified by oral sources - testimonials of activists and health professionals/managers who have led the organization of healthcare for people with HIV/Aids in the state. This research reveals that the lack of coordination between healthcare institutions and the dearth of any real political will to fight the epidemic in the state have hampered the planning and execution of public strategies and actions covering the whole welfare system in the state.

Keywords: health policies; Aids; history of health; Amazon. 
$\mathrm{A}$ história da Aids desde os primeiros casos identificados em 1981 esteve atrelada à história dos movimentos sociais em muitos países, no Brasil inclusive (Chequer, 2006). Descrever padrões epidemiológicos por si só não é suficiente para entender a dinâmica de disseminação de uma doença. Segundo Marques (2002, p.42) uma epidemia deve ser compreendida também como um fenômeno social que "mobiliza comunidades a revelar comportamentos que incorporam e reafirmam valores sociais". As epidemias evidenciam um comportamento coletivo, não acontecem aleatoriamente, sendo ainda produto da combinação de decisões políticas e do comportamento social de cada momento histórico em que surgem e se espalham.

Entender o contexto social, político e ideológico no momento de surgimento e expansão da doença é uma questão central, uma vez que, conforme entende Altman (1995), isso definirá alocação de recursos, qualidade da atenção e investimento em pesquisa sobre o tema, interferindo na vulnerabilidade das populações. Uma pesquisa preliminar nas bases de dados bibliográficos Lilacs e Scielo apontou que as produções científicas sobre o tema no estado do Amazonas publicadas até o momento não têm abordado o problema de forma detalhada quanto aos aspectos sociais e históricos da epidemia em solo amazonense. O presente artigo é parte de um estudo acerca do ativismo do movimento social de Aids no Amazonas, análise que não seria possível sem um entendimento histórico sobre a emergência da epidemia. Assim, este trabalho visa contextualizar a história do programa de Aids no Amazonas desde os primeiros anos da epidemia, descrevendo o cenário social, histórico e em certa medida também político à época da emergência da doença e no qual a epidemia ganhou espaço ao longo dos anos.

O levantamento de dados se deu a partir de diversas fontes documentais: jornais do período, atas das reuniões do Conselho Estadual de Saúde e suas respectivas resoluções, planos e relatórios das intervenções realizadas pelas instituições de referência. Após esse levantamento, várias questões permaneceram em aberto, sinalizando a necessidade de realizar entrevistas com informantes-chave: gestores e profissionais de saúde que lideraram a organização dos serviços de assistência aos primeiros casos no Amazonas e ativistas que atuam na área desde então, no total de oito entrevistas. Os entrevistados concordaram em falar sob condição de sigilo, conforme previsto no Termo de Consentimento Livre e Esclarecido, tendo em vista que suas opiniões emitem juízo de valor sobre a condição da qual falam. Por esse motivo foi identificado apenas o grupo ao qual o entrevistado pertence (gestor, ativistas etc.). Esse método mostrou-se apropriado para, conforme entende Britten (2009), esclarecer informações e explorar detalhes. O relato das fontes orais nos permitiu entender a complexidade dos mecanismos da tomada de decisão, articulações políticas, influências e pressões próprias do momento histórico e social do período. Delimitamos nossa análise no período de 1986, quando houve a notificação do primeiro caso no Amazonas, a 2010, ano com dados consolidados no Boletim Epidemiológico do Ministério da Saúde até o início da pesquisa.

Há extensa produção na literatura apontando que, nos países centrais, a descoberta da Aids esteve desde sempre associada à luta pela manutenção dos direitos civis conquistados a duras penas, especialmente nas duas décadas anteriores à epidemia (Mann, 1996; Gruskin, Mills, Tarantola, 2007; Altman, 1995). No Brasil, da mesma forma, a Aids forçou as autoridades de saúde a estabelecer um diálogo com a sociedade, especialmente com os grupos mais 
afetados pela doença (Chequer, 2006; Bastos, 2006; França, 2008; Grangeiro, Teixeira, 2009). No Amazonas, as respostas pioneiras vieram de poucos dedicados profissionais que conseguiram dar certa visibilidade ao problema em meio a um serviço de saúde ainda em estruturação (Benzaken et al., 1998).

\section{O cenário brasileiro: política, sociedade e saúde}

Junto com a tomada do poder político pelos militares em 1964, Barata (2000, p.340) ressalta que na década de 1960 "teve início o modelo econômico centrado no fortalecimento do capitalismo privado e fomento ao capital estrangeiro" e que o controle da inflação se daria a partir do congelamento dos salários. Consequência dessa política salarial foi o fato de que, embora o país crescesse em torno de $10 \%$ ao ano, com salários congelados, a maioria das pessoas não se beneficiou com o aumento dessas riquezas, reforçando a pauperização da população.

No campo da saúde, à medida que o poder aquisitivo da população decaía, o acesso à saúde ficava mais caro e difícil. Paim et al. (2011, p.17) apontam que essas reformas governamentais levaram ao crescimento de um sistema de saúde predominantemente privado e que o "mercado da saúde baseado em pagamento por serviços prestados por operadores privados aliado aos efeitos da recessão econômica alimentaram anseio por reformas profundas no setor saúde".

O movimento da Reforma Sanitária, reunindo iniciativas de grupos de base como professores, pesquisadores, sindicatos e profissionais de saúde, ao defender saúde não como "uma questão exclusivamente biológica a ser resolvida pelos serviços médicos, mas sim como uma questão social e política a ser elaborada" (Paim et al., 2011, p.18), lançou as referências para alavancar as reformas almejadas pela sociedade. A Reforma Sanitária, em coerência com o discurso de promoção dos direitos individuais em evidência no mundo e com o processo de redemocratização política do país, trazia o claro entendimento de que a saúde é um direito humano, e assegurar esse direito é dever do Estado.

A criação do Sistema Único de Saúde (SUS), respaldado pela Constituição de 1988, foi fundamental para o desenvolvimento da política brasileira de Aids que se desenharia nos anos seguintes. O programa brasileiro no controle da epidemia não teria logrado êxito e reconhecimento internacional sem a existência do SUS (Bravo et al., 2006). O mesmo se pode dizer sobre o sentido de controle social. A participação popular na elaboração e fiscalização das políticas de saúde é resultado do processo de redemocratização que o país discutia naquele momento. No caso da Aids, desde muito cedo, os grupos vulneráveis de São Paulo foram chamados a participar das discussões iniciais quando a epidemia tocou solo nacional (Chequer, 2006; França, 2008).

Vale notar que as propostas da Reforma Sanitária foram bastante revolucionárias à época, uma vez que no mundo se expandia a ideologia neoliberal que propunha a diminuição da intervenção do Estado na economia e nos mercados. A proposta de um sistema de saúde público estava na contramão do que então se considera "moderno". Para Marques (2002, p.50), a combinação de todos esses elementos é fundamental para compreender o delineamento da resposta brasileira à Aids:

Ao se articularem os crescentes movimentos sociais, os princípios e diretrizes que marcaram, ainda que com dificuldade de implantação, uma mudança de sistema de saúde 
no Brasil, e o início do processo de redemocratização, formaram o pano de fundo para que os sujeitos dessa história dessem início à construção da política de enfrentamento à Aids/HIV no país.

A assistência aos casos iniciais a partir de 1982, quando foi diagnosticado o primeiro caso de Aids em São Paulo, embora tenha sido reconhecido retrospectivamente um anterior, em 1980 (Galvão, 2002), foi dramática. Vale lembrar que no momento "pré-SUS" a assistência médica cabia ao Inamps e a assistência hospitalar era feita em seus hospitais. A Aids, todavia, era vista como um problema de saúde pública, cuja responsabilidade cabia às secretarias estaduais de saúde, que, por sua vez, não tinham hospitais para atender à demanda crescente.

Assim, num cenário de redemocratização política, crise econômica, discussão sobre reforma sanitária, de fortalecimento dos movimentos sociais de base e de luta por direitos civis, a Aids chega ao Brasil.

\section{A emergência da Aids no Amazonas: cenário político e social}

Com o objetivo de integrar econômica e socialmente a região Norte ao resto do país, o governo militar empreendeu projetos de grande porte, como construção de extensas rodovias e hidrelétricas na região. Sob o lema "integrar para não entregar", o governo propunha a ocupação da região para resolver duas questões: por um lado, assegurava a presença do Estado brasileiro nesse vasto território, por outro, aliviava a tensão social por espaços agrícolas tradicionais no resto do país, sem alterar o sistema fundiário.

O mais importante projeto econômico foi a implantação da Zona Franca e do Polo Industrial de Manaus. Em 28 de fevereiro de 1967, pelo decreto-lei n.288, o governo militar adota um modelo de zona franca no qual a região passa a receber incentivos fiscais para ser implantado um polo industrial, comercial e agropecuário, tendo como centro a cidade de Manaus. Segundo Virgílio Neto (2008, p.149), o objetivo dos militares com a Zona Franca de Manaus (ZFM) foi "ocupar a região amazônica, dado seu elevado conteúdo estratégico decorrente das riquezas naturais, da baixa densidade demográfica e do grande interesse internacional".

Seráfico e Seráfico (2005) argumentam que para tal desenvolvimento era indispensável prover a região de infraestrutura e condições de vida para atrair força de trabalho e investimentos nacionais ou estrangeiros. Esse modelo trouxe um dinamismo à economia da região em curto tempo, gerando um impacto gigantesco na receita do estado e da capital. Nascimento (2004) aponta que, entre 1968 e 1974, a receita de Manaus cresceu 922\%, e a do estado teve aumento de $547,7 \%$. Por um lado, isso significou superação da economia extrativista, mas por outro gerou êxodo rural com abandono de culturas tradicionais.

Nas décadas seguintes o crescimento populacional acentuou-se, com pessoas vindas de todo o interior do estado e outras regiões do país em busca de oportunidade de crescimento e renda nas indústrias recém-instaladas no Polo Industrial de Manaus. Numa série histórica, Rivas (2003) analisa que a população de Manaus aumentou oito vezes entre 1960 e 2000.

Desde sua criação, em 1967, até 1970, o comércio principalmente de produtos importados era a principal atividade geradora de emprego. Manaus só viria abrigar um quantitativo 
expressivo de indústrias a partir da segunda metade da década de 1970 (Rivas et al., 2009). Em consequência, na década seguinte se intensificou ainda mais o crescimento populacional (Gráfico 1).

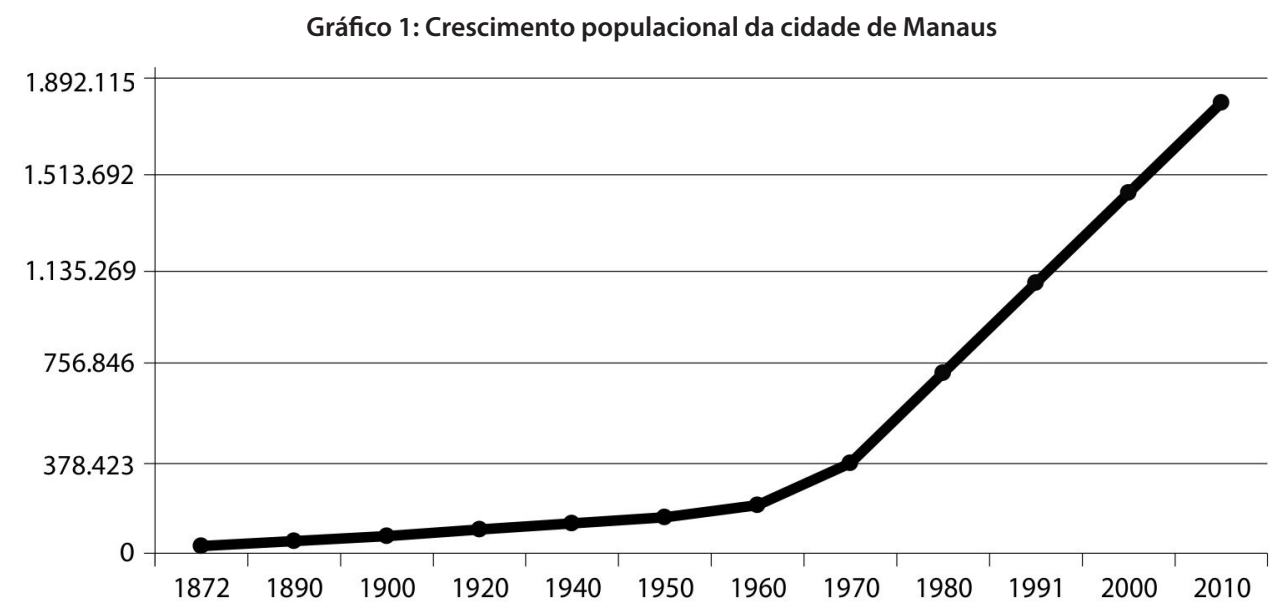

Fonte: IBGE, 2012.

Todo esse rápido crescimento populacional, financeiro e industrial não foi acompanhado de investimentos ou estruturação dos serviços da cidade. Jornais da época noticiavam que a cidade vivia uma crise habitacional (Manaus sofre..., 4 mar. 1986), sendo que diversos bairros surgiram à margem do poder público. Ocupações desordenadas de áreas urbanas proliferaram especialmente nas áreas no entorno do Distrito Industrial, zona leste de Manaus. Por isso Nascimento (2004) entende que a ZFM não se caracterizou como um projeto, mas se impôs como uma realidade, agravando as condições sociais de moradia, saneamento, serviços de saúde e transporte.

A saúde foi um setor que sentiu fortemente o impacto dessa explosão demográfica. A proposta política da ZFM não contemplava qualquer intervenção nessa área; no entanto, foi notável que a demanda por serviços sanitários e de saúde produzisse uma mudança no modo como a saúde era organizada até então.

A primeira mudança sentida foi a criação de cursos na área da saúde dentro da Universidade do Amazonas (UA), atual Universidade Federal do Amazonas. A formação profissional superior no estado estava paralisada desde a crise da borracha, pois as instituições de formação eram em grande parte financiadas pelos grandes produtores. Especialmente após o Golpe de 1964, havia necessidade de qualificar pessoas em nível superior para ocupar os novos postos que estavam a ser criados, inclusive na área da saúde.

Em ofício encaminhado ao reitor da UA, o governador Arthur César Ferreira Reis solicita a instalação das faculdades de medicina, farmácia e odontologia para suprir carência de assistência de saúde na capital, mas principalmente no interior (Brito, 2011). Nesse ofício, o governador se comprometia em confiar o Hospital Getúlio Vargas, à época o único hospital geral, sob gestão estadual, para que ali se instalassem as escolas e enfermarias para campo prático dos estudantes. Esse hospital foi inaugurado em 1965 por iniciativa do governo do 
estado já como resposta ao aumento da demanda por assistência à saúde, considerando que, com uma população de aproximadamente trezentos mil habitantes, apenas os leitos filantrópicos não respondiam mais às necessidades (Albuquerque, Cóvas, 1998). As faculdades de medicina, farmácia, odontologia e ainda engenharia começaram a funcionar efetivamente a partir de 1966. Em 1971 se formou a primeira turma de médicos do estado (Brito, 2011).

Em 1971, além desse hospital, a cidade contava na rede pública de assistência com três unidades de atendimento especializado: Dispensário Alfredo da Matta, para hanseníase; Cardoso Fontes, para tuberculose; e Eduardo Ribeiro, para saúde mental, e cinco postos de saúde para atendimento ambulatorial. Além dessas instituições de gestão exclusivamente pública, havia ainda três hospitais de grande porte: Santa Casa de Misericórdia, Beneficência Portuguesa e Hospital Militar, instituições que recebiam apoio do governo mas não estavam sob sua administração direta (Ricci, 1974). Segundo Albuquerque e Cóvas (1998), outras unidades de assistência e serviço foram criadas na década de 1970 - entre elas o Laboratório Central de Saúde Pública, o Banco de Sangue Central de Manaus, o Hospital de Moléstias Tropicais e o Centro de Controle de Oncologia, além da Secretaria de Saúde do município.

Com o crescimento populacional, a saúde sentiu o impacto do aumento de demanda por serviços e a limitação das unidades de assistência que existiam até então. Em 1975, quando foi criada a Secretaria Municipal de Saúde (Semsa), todos os setores da sociedade sentiam a necessidade de repensar a saúde pública, especialmente em Manaus:

O aumento do contingente populacional e a complexa problemática que o acompanha, exigiram do Poder Público adequação de estruturas prestadoras de serviço para alcançar os objetivos que se propõe, razão pela qual, através da Lei n.1.240 de 20 de novembro de 1975, foi criada a Secretaria Municipal de Saúde, órgão do primeiro escalão da Administração Municipal (Semsa, s.d.).

Embora instalada há mais tempo, a Secretaria Estadual de Saúde (SES) também passou por diversas mudanças e reestruturação organizacional durante esse período. Entre 1965 e 1984, a secretaria passou por cinco processos de reorganização, sempre tentando se adequar para responder não apenas à demanda de assistência, mas, principalmente, às mudanças na estrutura política do estado (SES, s.d.).

Aumento populacional, intenso fluxo de pessoas (migratório e turístico), rede de saúde em organização configuram o cenário local quando, em 1986, o primeiro caso de Aids foi notificado no Amazonas.

\section{A organização da resposta estadual e a evolução da epidemia O protagonismo da Fundação Alfredo da Matta}

Em agosto de 1975, cria-se a Divisão Nacional de Dermatologia Sanitária (DNDS), antiga Divisão Nacional da Lepra, dentro do Ministério da Saúde. Além da hanseníase, esse departamento passou a ocupar-se também da leishmaniose, pênfigo e das doenças sexualmente transmissíveis.

Entre 1978 e 1979, a primeira ação no Amazonas de assistência especializada em saúde sexual/doenças sexualmente transmissíveis (DST) foi organizada no então Centro de 
Dermatologia Tropical e Venereologia Alfredo da Matta. ${ }^{1}$ Embora com aval da Secretaria de Saúde, a instalação do serviço foi uma iniciativa do diretor clínico da instituição, médico Sinésio Talhari. A contratação de especialistas em urologia e ginecologia ${ }^{2}$ tinha o objetivo de prover a assistência a portadores de DST, desenvolver estudos a respeito e contribuir para a formação de profissionais para outras instituições (SES, 1997, 1999). Relatos orais de gestores entrevistados apontaram que, após alguns embates e acordos internos, em 1981 é criado, nas dependências do Alfredo da Matta, o ambulatório de DST, primeiro serviço dedicado à assistência de portadores de DST no estado. À frente do serviço foram designados a médica Adele Benzaken (para atendimento às mulheres) e o médico José Carlos Sardinha (assistência aos homens).

Sardinha (SES, 1999, p.17) conduziu o estudo "A conta do desperdício: estudo simulado sobre atendimento de portadores de DST nos balcões de farmácia e drogarias de Manaus" e estimou que apenas 10\% dos casos de DST eram atendidos no serviço público, sendo o restante dos casos sintomáticos atendidos nos balcões de farmácia. Para o autor, o descontrole das DST invariavelmente significava descontrole também do HIV. Os relatos dos profissionais ouvidos nessa pesquisa apontaram que os casos que chegavam ao serviço nesse período apresentavam estágios avançados dessas infecções.

Até 1985 com centenas de casos de Aids em todas as regiões do país, os estados desenvolveram suas próprias estratégias para lidar com a epidemia, uma vez que não havia diretiva clara nem apoio organizado em nível nacional. No Amazonas, os gestores à época relataram que a Fuam e o Centro de Hematologia do Amazonas (Hemoam) passaram a se reunir em grupos de estudo, já atentos à eminente chegada da Aids ao estado, embora ainda nenhum caso tivesse sido diagnosticado até então.

Por meio da portaria n.236 de 1985, o Ministério da Saúde estabeleceu as diretrizes para o Programa de Controle da Aids, sob a responsabilidade da DNDS. Em 1986, a Aids passa a ser uma doença de notificação compulsória, mesmo ano em que o primeiro caso de Aids foi notificado no Amazonas. O DNDS credencia o Alfredo da Matta como Centro de Referência e Treinamento para DST da região Norte (SES, 1997).

O curso lógico seria a assistência aos soropositivos também permanecer sob responsabilidade dessa instituição; todavia, os relatos dos profissionais envolvidos apontaram que embates internos entre equipe clínica e as religiosas que permaneciam na gestão do Alfredo da Matta, aliados à falta de leitos para internamento, impossibilitaram que o espaço acolhesse também os casos de Aids.

A epidemia se espalhava rapidamente no território nacional. Até 1990 quase nove mil casos já haviam sido reportados em todo o país - sessenta deles no Amazonas, e todos concentrados na capital (MS, 2012a).

O Programa Nacional de DST/Aids apoiou em todas as regiões do país a organização de centros de referência. No Amazonas, com o aval da Secretaria Estadual da Saúde, o Ministério da Saúde delegou à Fundação Alfredo da Matta, que já era referência regional para DST, a responsabilidade de organizar as bases de um programa de controle também de Aids. Um técnico da instituição foi designado para coordenar essas ações, o médico José Carlos Sardinha (SES, 1999). 
Em novembro de 1987 foi realizado em Brasília o Primeiro Encontro Nacional de Coordenadores Estaduais DST/Aids no qual cada coordenador apresentou a situação em seu estado. A equipe de coordenação do programa no Amazonas era formada por dois médicos - José Carlos Sardinha e Adele Benzaken - uma enfermeira e um sociólogo emprestado da Secretaria de Saúde (MS, 1987).

O relatório apresentado apontou que o principal objetivo estratégico dessa coordenação deveria ser sensibilizar instituições e profissionais de saúde para assumir ações de controle e prevenção das DST e Aids, e que o insucesso do programa podia ser atribuído em parte à inabilidade da coordenação em promover tal sensibilização, mas também a outras condições preexistentes. Segundo o documento, as instituições mais envolvidas com o programa, além do Alfredo da Matta, eram a SES, ${ }^{3}$ a Fundação de Serviços de Saúde Pública (FSESP), a UA, a Semsa Manaus e o Inamps. Cada uma com grau de envolvimento e dificuldades específicos.

A SES deveria ser a instituição na liderança do processo; no entanto, o relatório aponta que ela passava por "problemas crônicos" de organização cuja resolução dependia de uma "forte decisão política". De fato, diversos documentos levantados na pesquisa apontam que só na década de 1980 a secretaria passou por duas reorganizações em sua estrutura (1981 e 1984) e mudança de dez secretários, sendo os anos mais críticos 1987, com quatro trocas de gestores, e 1989, com mudança de três gestores e ainda uma comissão administrativa. Conforme o documento, a secretaria estava sujeita a imperativos políticos, sem ordem administrativa, servidores desqualificados e sem estímulos técnicos e financeiros para engajamento em ações de maior eficácia. As ações do programa esbarravam nesses entraves administrativos.

Mesmo dentro da Fuam, o programa de DST/Aids tinha dificuldade em coordenar ações, uma vez que a instituição era histórica e prioritariamente dedicada à hanseníase. As fontes utilizadas no trabalho apontaram que os embates eram tanto com o corpo técnico (equipe clínica) quanto com o administrativo (entidades religiosas permaneciam na gestão vindas da assistência aos hansenianos): "O programa de DST/Aids ainda é considerado como o primo pobre do programa de hanseníase, veleidade do pequeno grupo que a ele se dedica e a que se dá atenção se não houver, no momento, alguma atividade do programa de hanseníase, sempre prioritário" (MS, 1987, p.4).

A FSESP, embora o relatório conclua que tinha os profissionais menos qualificados, foi considerada a instituição mais bem engajada nas ações em DST-Aids, com protocolos bem estabelecidos e treinamentos regulares de suas equipes. A Semsa Manaus, mesmo contando com interesse de alguns de seus gestores, não tinha atuação expressiva no programa e sofria dos mesmos problemas estruturais da SES, embora a situação fosse menos caótica. Já o Inamps apresentava resistência a ações rotineiras em DST.

A UA, segundo o relatório, dava suporte aos serviços de assistência a soropositivos. Nas dependências do Hospital Universitário Getúlio Vargas eram tratados doentes de Aids que necessitassem de internamento, especialmente nos cinco primeiros anos da epidemia. No Ambulatório Araújo Lima, da Faculdade de Medicina, um serviço de DST foi montado, e no seu hemocentro era feita a sorologia para o vírus.

Fazendo uma análise mais detalhada do pano de fundo da situação, destacamos que, no Amazonas, o despreparo da equipe em lidar com a epidemia não foi diferente do resto do país. A Aids impôs (e impõe) desafios iguais às autoridades de saúde de todo o mundo. 
Até 1987, com um falho sistema de informação, nem mesmo o ministério tinha meios para avaliar sua própria atuação.

Outro ponto é o contexto nos quais os pioneiros estavam inseridos. O que marcou a diferença na resposta organizada nos estados brasileiros foi a capacidade que suas secretarias de Saúde tiveram de identificar a doença como uma emergência de saúde pública e que, independentemente do número de casos registrados, a epidemia acabaria por atingir todos os cantos do país indiscriminadamente. Marques (2002) observa que as possibilidades políticas do setor saúde instaladas localmente no período foram determinantes para as respostas iniciais à epidemia nas diversas regiões do país. Para ilustrar seu posicionamento, a autora destaca que, em 1983, quando havia apenas quatro casos confirmados em São Paulo, sob a liderança de sanitaristas daquela secretaria fortemente comprometidos com princípios da reforma sanitária, já se organizava o primeiro programa de combate a Aids no Brasil, que, segundo Galvão (2002), estabeleceu as bases para a posterior organização de outros estados e até mesmo do programa nacional.

Sem o suporte da Secretaria Estadual de Saúde, que também estava desestruturada à época, o Programa de DST/Aids do Amazonas dificilmente conseguiria implantar ações preventivas e de assistência em abrangência estadual (SES, 1999). Analisando a situação da SES desde sua criação, em 1956, até 2010, a secretaria passou por oito reestruturações administrativas e troca de 38 secretários. Isso significa que, em média, cada gestor permaneceu no cargo cerca de 16 meses, confirmando a instabilidade da situação dessa secretaria (SES, s.d.).

As autoridades de saúde do Amazonas demoraram a perceber a ameaça que a Aids representava; a tomada de consciência da gravidade da epidemia aconteceu aos poucos. Para exemplificar essa mudança de postura, citamos o caso do então diretor da Fundação de Medicina Tropical (FMT), ${ }^{4}$ personalidade influente no âmbito da saúde, médico Heitor Dourado. Em entrevista ao Diário do Amazonas (Aids mata..., 8 mar. 1987), declara que a Aids era um problema menor entre outras doenças sanitárias, muito mais preocupantes. Mas já no ano seguinte reconhece a pertinência do tema e o inclui na pauta do $24^{\circ}$ Congresso da Sociedade Brasileira de Medicina Tropical, realizado em Manaus e organizado por aquela instituição (Congresso destacará..., 21 fev. 1988).

A epidemia avançou.

Como Centro de Referência em DST, ao longo dos anos, a Fundação Alfredo da Matta seguiu liderando uma série de estudos e pesquisas no estado, em parceria principalmente com o Ministério da Saúde. Esse protagonismo histórico faz com que a instituição ainda hoje tenha assento como membro da comunidade científica na Comissão Nacional de Aids, resultado de sua liderança em diversos projetos-piloto de intervenção, estudos de validação de modelos de assistência e novos protocolos e suporte na implantação de novas políticas para o Ministério da Saúde, desenvolvendo também políticas de atenção aos indígenas. Além disso, liderou ainda algumas outras intervenções inovadoras que destacaremos mais adiante.

\section{A Aids na Fundação de Medicina Tropical}

Relatos de profissionais de saúde que prestavam atendimento aos primeiros casos caracterizaram a situação da assistência no Amazonas. Os técnicos do Alfredo da Matta iniciaram um diálogo com a SES para criação do Programa Estadual de Aids, uma vez que 
esses pacientes eram atendidos precariamente em seu ambulatório de DST. Sem uma rede de assistência, os hospitais resistiam em internar soropositivos e muitos profissionais se recusavam a atendê-los. As internações eram conseguidas na base de troca de favor e embates entre profissionais e gestores.

Com o aumento de casos, pressão da sociedade, da mídia e muita articulação, em fevereiro de 1989, por determinação da Comissão Interinstitucional de Saúde, foi criado o Programa Estadual de DST e Aids, em uma tentativa de melhor coordenar a resposta estadual entre as instituições envolvidas (SES, 1999).

Assim, num acordo entre a Coordenação Estadual DST/Aids, a FMT e a SES, foi construída nas dependências dessa fundação uma ala de isolamento com dez leitos para atender especialmente aos soropositivos. ${ }^{5}$ A FMT tornou-se referência para atendimento clínico/ ambulatorial às pessoas vivendo com HIV/Aids. Para facilitar a articulação necessária para assistência adequada aos pacientes, a coordenação do programa transferiu-se para lá, permanecendo ainda sob liderança de um técnico da Fuam, Adele Benzaken (SES, 1999).

A decisão de tornar a FMT o hospital de referência para assistência da Aids, assim como lotar a Coordenação Estadual em suas dependências, como veremos, traria algumas repercussões para a história da Aids no Amazonas, embora à época tenha sido a solução possível.

A criação de espaço físico não significou automaticamente assistência integral aos soropositivos. Assim como a Aids enfrentou resistência na Fuam, igualmente os profissionais da FMT resistiam ao acolhimento do serviço. Também no Amazonas os primeiros anos da epidemia foram marcados por ausência de leitos, negligência e preconceito dos profissionais de saúde. Os profissionais que se prontificaram a prestar o mínimo de assistência paliativa sofriam o estigma de lidar com "doença procurada", que carregava pesado questionamento moral da sociedade. Segundo uma profissional de saúde: "Dentro do Alfredo da Matta nós tínhamos muitos problemas, quando chegava paciente no ambulatório e precisava de internação. Aí era toda uma negociação para onde levar ... Além desse problema de não conseguir internação, todos os médicos diziam que eu era uma doida: 'ei! tu te mete com cada coisa'".

A atualmente denominada Fundação de Medicina Tropical do Amazonas, foi criada em 1974 como Hospital de Moléstias Tropicais por iniciativa de dois médicos docentes da Universidade do Amazonas: Carlos Borborema e Heitor Dourado. O trabalho iniciou com uma pequena enfermaria dentro Hospital Getúlio Vargas, servindo de campo de estágio para um grupo de estudantes que, nos anos seguintes, deram continuidade à trajetória desses professores, prosseguindo na vanguarda das pesquisas e na assistência às doenças infectocontagiosas na região (Pedro Teixeira..., 2012).

Assim como a hanseníase era prioridade na Fuam, as doenças tropicais eram (e são) para a FMT, com a diferença que, na primeira, a iniciativa para criação de serviço DST tinha partido da direção da instituição.

Em 1987, embora o Amazonas tivesse registrado apenas cinco casos, o Boletim Epidemiológico (MS, 2001) já apontava a dimensão que a Aids vinha tomando no país: quase três mil casos, com 2.223 óbitos.

No Amazonas, os primeiros gestores do programa denunciaram a "falta de vontade política" em priorizar o controle DST/Aids e a falta de plano estratégico com ações interinstitucionais 
que dessem conta de forma consistente e sustentável do combate à epidemia (Benzaken et al., 1998; SES, 1999). Profissionais de saúde entrevistados sinalizaram que, quando a Coordenação Estadual instala-se na FMT, extingue-se a Comissão Interinstitucional de DST/ Aids (formada pela FMT, Fuam e a Fundação de Hematologia do Amazonas), o que contribui para o enfraquecimento da rede e a desarticulação das ações entre os atores envolvidos no combate à epidemia.

Embora presente, não se percebe até aqui a liderança da Secretaria de Saúde na organização da resposta de controle à Aids. Os dados apontam que essa iniciativa fica restrita à atuação de alguns profissionais sensíveis à questão. Assim sendo, dificilmente seria possível um plano eficaz de enfrentamento à epidemia de abrangência em todo o estado. A secretaria adotou a postura de delegar o enfrentamento à Aids às autarquias a ela afiliadas.

\section{Algumas iniciativas exitosas, contudo isoladas}

No Amazonas, embora a Fuam tenha desenvolvido inúmeras intervenções, destacamos duas iniciativas que trouxeram interessantes resultados e inovação por sua capacidade de articular em rede de assistência. A primeira e de maior abrangência ocorreu a partir de 1995, quando a Secretaria Municipal de Saúde de Manaus decidiu implantar em toda a rede básica do município assistência a pessoas portadoras de DST com abordagem sindrômica. No ano seguinte, o serviço já estava em funcionamento em 17 unidades do município. A estratégia visava principalmente tratar adequadamente os casos, diminuindo assim a incidência de DST e consequentemente HIV na capital (SES, 1999). Além da rede de cuidado estabelecida, outra inovação foi que cada centro de saúde tinha um plano de ação com indicadores e metas estabelecidas, além de encontros coletivos regulares para monitoramento e avaliação.

Foi firmada uma parceria entre a Fuam e a Semsa Manaus, cabendo à fundação realizar treinamento em abordagem sindrômica das equipes nas unidades dessa secretaria e realizar visitas técnicas para acompanhar a implantação do programa. Os treinamentos e acompanhamento aconteciam ao longo do ano, culminando no Simpósio de DST no último trimestre. O primeiro simpósio ocorreu em outubro de 1996, e era o espaço no qual as equipes apresentavam as ações desenvolvidas em cada zona da cidade. Em contrapartida, a Semsa assegurava aquisição de medicamentos, material educativo, contratação de profissionais, custeio dos treinamentos, adequação/ampliação da estrutura física para atendimento. Como consultor do projeto, Sardinha ressalta que tal iniciativa só logrou sucesso por conta da priorização dada pelo gestor Tirso Rodrigues, que esteve à frente da secretaria entre 1995 e 1997 (Semsa, 1997).

No período de centralização das decisões no nível federal, Sardinha reitera a importância do sucesso dessa iniciativa na captação de recursos financeiros junto à Coordenação Nacional para a capital. Esse programa foi reconhecido até pela Organização Mundial da Saúde como exemplo de boa prática em saúde (Semsa, 1998). Os simpósios continuavam a ocorrer regularmente ainda em 2010.

Com a mudança de gestão, o Programa Municipal de DST/Aids foi perdendo fôlego. Informações analisadas apontam que essa iniciativa (até hoje talvez a única no estado) sistematicamente incorporou o rastreio e o tratamento de DST na abordagem sindrômica na rede de saúde, promovendo articulação em rede de assistência e engajando profissionais 
de várias unidades em ações de tratamento, prevenção e educação (Semsa 1997, 1998). No entanto, com a Aids não se podia assegurar a mesma cadeia de cuidado, uma vez que casos positivos eram referenciados à FMT. Em caso de diagnóstico de Aids, o serviço referenciava, mas a contrarreferência era perdida.

Em outra iniciativa de caráter interinstitucional, a Fuam desenvolveu com a Prefeitura de Manacapuru o Projeto Princesinha, um plano de prevenção das DST/Aids no município (1997-2004). Benzaken et al. (2007), ao descreverem os resultados desse programa, deixam claro que seu sucesso só foi possível pelo comprometimento da equipe de saúde daquela secretaria, e principalmente pela priorização política dos gestores do município recém-eleitos e que tinham interesse em desenvolver turismo ecológico.

O projeto logrou por alguns anos repercussão nacional, sucesso devido principalmente à utilização da metodologia Educação de Par com profissionais do sexo, público-alvo priorizado pela intervenção. Além das ações específicas para esse público, foi estabelecida assistência na rede básica de saúde do município às pessoas portadoras de DST, assegurando-lhes acesso ao diagnóstico, tratamento adequado, aconselhamento e testagem para HIV. Como era uma prioridade, o Programa de Controle das DST/Aids de Manacapuru foi regulamentado, com provisão orçamentária garantida pela Prefeitura, incluindo compra de medicamentos e implantação de sistema de vigilância epidemiológica. Com a mudança do grupo político no município, houve um realinhamento das prioridades, e o projeto perdeu força.

\section{A Aids e o Conselho Estadual de Saúde}

As atas de reunião do Conselho Estadual de Saúde (CES) forneceram pistas interessantes sobre a importância com que algumas questões de saúde foram tratadas pelo poder público ao longo dos anos.

No caso da Aids, desde a organização do CES, em 1993, a primeira vez que o tema entrou na pauta de discussão foi na $33^{\text {a }}$ Reunião, de 14 de janeiro de 1997, quando o então conselheiro Tancredo Soares relatou a exitosa experiência da Semsa Manaus (CES, 3 jun. 1997). No seu entendimento, o programa de Aids deveria ser assumido pelo CES juntamente com setores envolvidos da SES, FMT e Coordenação Estadual DST/Aids. Embora fosse um mau entendimento acerca da responsabilidade do CES, fato é que Soares apontava a necessidade de a Secretaria Estadual assumir responsabilidade pelo programa.

Aliás, o Programa de Aids começa a ter visibilidade no âmbito estadual especialmente quando Tancredo Soares - que já vinha sensibilizado com o tema desde sua gestão na FMT - assume a Secretaria Estadual de Saúde em 1997. Nas atas de 1994 a 2010, o maior número de vezes que o tema Aids esteve na pauta e com discussão mais detalhada aconteceu precisamente quando Soares esteve presente, seja na condição de membro (conselheiro) ou como presidente (secretário de saúde). Relatos também confirmam que o médico mostrou-se sensível à problemática e é um nome importante na história dos primeiros anos da epidemia no estado.

A precariedade do sistema de informação sanitária/epidemiológica é outro tema recorrente no CES. Na terceira reunião ordinária foi apresentada a situação de saúde no Amazonas, citando-se cólera, malária, sarampo e meningite como os grandes problemas do estado (CES, 21 jan. 1994). Nesse tipo de avaliação, comumente, o único critério utilizado é o número de 
casos, desconsiderando outros riscos eminentes como a Aids, por exemplo. Somente naquele ano foram registrados 86 novos casos no estado (MS, 2012a).

A ata da $34^{a}$ reunião, em março de 1997, menciona a condição de desestruturação do Programa Estadual. Àquela altura, embora a coordenação já estivesse sob responsabilidade de um técnico da FMT - médico Flávio Barros -, a Fuam permanecia sendo o Centro de Referência parceiro do PN-DST/Aids, rivalizando, de certa forma, com a FMT. A ata refere um relatório apresentado por Barros em que denuncia que "algumas pessoas estariam atuando no sentido oposto aos propósitos do programa" (CES, 10 mar. 1997, p.4). Nessa mesma reunião, Soares, já na condição de presidente do CES, expôs o sucesso da parceria entre a Fuam e a Semsa Manaus, sugerindo que proposta semelhante fosse implantada nas Unidades de Saúde do estado. Pela primeira vez, a SES parecia disposta a assumir liderança do Programa Estadual DST/Aids, apaziguando, assim, os desentendimentos entre Fuam e FMT. Em junho do mesmo ano, o assunto voltaria à pauta de discussão durante a plenária da 39a Reunião do Conselho. O presidente confirma que a Coordenação do Programa DST/Aids firmara alguns contratos diretamente com o Ministério da Saúde para redefinir a situação da Aids no estado (CES, 3 jun. 1997). Na reunião seguinte, definiu-se que seria convocado um encontro para elaborar uma proposta para o Programa DST/Aids no estado (CES, 24 jun. 1997). A proposta foi de que a Semsa Manaus assumiria a capital, cabendo à Secretaria de Saúde atender no interior.

No entanto, a Fuam prosseguiu liderando intervenções em DST no Amazonas, interiorizando ações e projetos. Como uma autarquia, a fundação dispõe de certa autonomia para estabelecer parcerias internacionais, facilitando captação recursos de fontes externas e independentes da Secretaria Estadual.

\section{Uma nova fase: os acordos com o Banco Mundial, a Política de Incentivos e o Programa Estadual}

O Ministério da Saúde centralizou o planejamento estratégico e os recursos no nível federal depois da assinatura dos primeiros acordos com o Banco Mundial, a partir de 1993. Para Grangeiro et al. (2010), embora a medida fosse em direção contrária às diretrizes operacionais do SUS, foi essa centralização técnico-financeira que permitiu ao país dar uma resposta mais assertiva, coordenada e rápida a um quadro que se pintava desastroso no início dos anos 1990, com alarmante dissipação da epidemia em meio à população. Por outro lado, a concentração do conhecimento técnico no nível central não permitiu que capacidades institucionais fossem desenvolvidas em todos os estados brasileiros igualitariamente. O gerenciamento dos contratos que financiavam ações locais nos níveis estadual e municipal estavam sob supervisão do Programa Nacional, incluídos os projetos comunitários (MS, 1994).

Com a falta de apoio das autoridades de saúde locais, a Coordenação Estadual de DST/ Aids limitou-se a seguir as orientações da Coordenação Nacional (SES, 1999).

Numa avaliação mais recente feita por Grangeiro et al. (2011, p.S126), podemos ver como tal negligência nesses anos iniciais viria a afetar o curso da epidemia localmente até os dias de hoje. Sobre a descentralização da resposta à Aids no Brasil, concluem que nos municípios em que a responsabilidade pelo programa de controle e assistência foi assumida integralmente desde 1994, os programas "apresentaram uma maior chance de ofertar diagnóstico do HIV, possuir serviços de Aids e reduzir casos por transmissão sexual e por uso de drogas injetáveis" que os estados que assumiram o programa tardiamente a 
partir de 2003, reiterando a ideia de que decisões políticas efetivamente contribuem para a vulnerabilidade da população.

Dados do DataSUS mostram que em 1991 foram notificados os primeiros casos no interior do estado, um caso no município de Manaquiri e outro em Manicoré, distantes 54 quilômetros e 333 quilômetros da capital, respectivamente. No ano seguinte, outros cinco municípios também registraram casos (Beruri, Lábrea, Manacapuru, Parintins e Tefé), enquanto a capital já chegava a cinquenta casos (MS, 2012a, 2012b). Possivelmente, a precariedade do sistema de informação local também não facilitava uma adequada notificação dos casos.

Em 2001 foi apresentado na plenária do CES o Plano de Controle de Endemias do Estado. Embora a Aids no estado apresentasse clara tendência de crescimento, com a incidência de 11,8\%, nenhuma ação de controle/prevenção estava prevista nesse plano (CES, 6 mar. 2001). A doença permanecia invisível ao poder público, mas a epidemia se espalhava.

Com uma mudança nos rumos da política nacional a partir da assinatura do terceiro acordo com o Banco Mundial, em 2002, quando se tentou corrigir a verticalização e centralização no nível federal, adotando como diretrizes o "apoio à institucionalização, sustentabilidade e descentralização das ações à Aids no Brasil" (World Bank, 2004, p.32). Assim, o programa nacional, por meio da portaria ministerial n.2.313, instituiu novas regras sobre financiamento e gestão, o que ficou conhecido como "Política de Incentivos".

A 'Política de Incentivos' consiste em financiar Unidades Prestadoras de Serviço, por meio de mecanismos regulares do SUS. É a transferência fundo a fundo - repasse regular e programado de recursos diretamente do Fundo Nacional de Saúde para estados e municípios, independentemente de convênio ou instrumento similar. Destina-se ao financiamento das ações estratégicas e serviços de saúde para fortalecer a Política Nacional de DST e Aids (MS, s.d.; destaques no original).

As coordenações estaduais e municipais receberiam recursos por meio de transferência fundo a fundo, mas também deveriam assegurar uma contrapartida para cada ação do plano. Para isso deveriam elaborar seus Planos Anuais de Ações e Metas (PAM) com a participação da sociedade civil e aprovação nos respectivos conselhos de saúde.

No Amazonas, dos 62 municípios, apenas Manaus, Tabatinga e Parintins têm os critérios para receber repasse diretamente do MS. A assistência aos demais municípios está sob a responsabilidade da Coordenação Estadual DST/Aids. A Política de Incentivo mudou a organização da resposta local, forçando o estado e os municípios contemplados a assumir uma postura mais ativa na organização de seus programas.

A Secretaria Estadual é levada a assumir responsabilidade pelo programa, e o reestrutura em 2003, dentro do Departamento de Atenção Básica e Ações Estratégicas/Susam; contudo, por dificuldade de espaço físico, a coordenação permaneceu instalada no prédio da antiga Central de Medicamentos, que funcionava no terreno da FMT (CES, 16 dez. 2008). A unidade gestora (e também executora de várias ações) dos recursos vindos do PAM seria a FMT.

Em 2008, a direção dessa instituição encaminhou à SES uma proposta de reestruturação do Programa Estadual DST/Aids dentro da FMT. A proposta foi rejeitada sob o argumento de que o programa não era da fundação, e sim vinculado diretamente ao Departamento de Atenção Básica e Ações Estratégicas da Secretaria (Dabe/SES), e de que ele trabalhava "de 
forma intersetorial as áreas temáticas nos 62 municípios do estado do Amazonas" (CES, 16 dez. 2008). Esse fato foi muito celebrado pelas organizações da sociedade civil (OSC), pois reconheciam que, dessa maneira, as ações seriam planejadas de forma horizontalizada e integrada com outros programas:

A gente sempre acreditou que o programa tinha que ter uma inter-setorialidade, porque Aids antes matava... aí, com esse prolongamento de vida, começavam a aparecer alguns problemas: antirretroviral com câncer, antirretroviral com osteoporose, com tuberculose, até mesmo com fertilidade. Então a coordenação não poderia trabalhar isolada. Ela teria que trabalhar com o Programa de Hipertensão, de Nutrição, de modo transversal. A coordenação nunca conseguiu fazer isso (Ativista de OSC/Aids).

A resolução n.53 de 2008 resolveu que o Programa DST/Aids se instalasse nas dependências da SES a partir de janeiro 2009 e que os recursos passassem a ser gerenciados pelo Fundo Estadual de Saúde. O Dabe deveria apresentar uma proposta de reestruturação para o programa (CES, 16 dez. 2008).

Tal decisão desagradou profundamente a direção da FMT, que chegou a denunciar por vias legais o deslocamento de bens móveis dessa fundação para a SES. Sete meses depois, uma nova resolução ad referendum, alegando falta de espaço físico, aprovou o retorno da Coordenação para as dependências da FMT, lá permanecendo desde então (CES, 10 jul. 2009). O fato gerou frustração e descontentamento das OSC. Apesar de o discurso formal de alguns entrevistados confirmar que o programa está dentro do Departamento de Atenção Básica e Ações Estratégicas da Secretaria Estadual de Saúde, contraditoriamente, a Coordenação Estadual DST/Aids/HIV é parte do organograma da FMT.

A percepção generalizada das OSC é a de que o Programa Aids efetivamente é da FMT e não da Secretaria. Pode-se concluir que, sem a liderança da Secretaria Estadual de Saúde nesse processo, dificilmente ocorrerá um diálogo horizontal com os demais programas. É preciso que o enfrentamento à Aids se faça presente de modo transversal na política de saúde do estado, assegurando-se assim a presença de uma rede de assistência e cuidado em todo o Amazonas.

\section{Considerações finais}

No decorrer desta pesquisa nos deparamos com as dificuldades próprias de escrever sobre acontecimentos recentes e presentes no cotidiano. Descrever a sucessão de fatos que configuram a história da epidemia e da construção de uma resposta nos trouxe alguns desafios interessantes. Marcante foi registrar acontecimentos que permanecem tão vivos na memória dos entrevistados, fatos relembrados com forte expressão da subjetividade. Como a dinâmica da oralidade segue uma lógica diferente da escrita, outro desafio foi cruzar as narrativas com as informações documentais.

Como esperado já no início do trabalho, ter acesso a informações e/ou encontrar disponibilidade de dados não foi tarefa simples dentro das instituições que respondem pelo Programa da Aids no estado. Desde o princípio tomamos isso como um indicativo que nos fez refletir acerca de um ponto que tanto marcou a história da epidemia no Brasil em 20 anos, a participação da sociedade civil no acesso e diálogo com estruturas do governo. 
Outro elemento que emergiu nessa reconstituição da história foi a importância dada à epidemia. Se é verdade que "as respostas iniciais à epidemia vão ser diferentes nos diversos estados brasileiros, dependendo das possibilidades políticas que se instalaram no período nas esferas do setor saúde" (Marques, 2002, p.52), fatalmente o controle da Aids passa acima de tudo por uma decisão política.

Tradicionalmente, o que torna um problema uma questão de saúde pública são parâmetros epidemiológicos quase sempre baseados no número de casos detectados. O Amazonas, não diferente de muitos outros lugares, demorou a organizar uma rede de assistência para um problema que o mundo já reconhecia como epidemia.

Embora o Amazonas tenha contado com dedicados profissionais de saúde comprometidos com o enfrentamento da epidemia ao longo da história, entre as fontes analisadas parece haver consenso acerca da priorização dada ao tema dentro da estratégia de saúde do estado. As intervenções foram e ainda são feitas de forma isolada, carecendo de articulação entre as instituições de assistência. O combate à epidemia poderia lograr importante avanço com a organização de uma liderança capaz de se articular tanto com as instituições de governo quanto com a sociedade civil envolvida no enfrentamento à Aids.

Essa desarticulação pode ter sido resultado do modelo de gestão adotado pela Secretaria de Saúde ao delegar às suas autarquias a função de liderar a resposta dos diversos programas de saúde. Considerando o histórico do programa de Aids aqui relatado e as taxas alarmantes de incidência que o estado apresentava até 2010 (MS, 2012a), refletimos se essa forma de organização responde de forma satisfatória a necessidades impostas para controle da epidemia. Indagamos, ainda, num cenário em que as doenças tendem a se cronificar, se é adequado manter um modelo tão verticalizado.

Ao longo da pesquisa, ficou claro que a atual organização do Programa de Aids não é obra do acaso, mas produto também da história e das decisões políticas e técnicas tomadas até aqui. Embora o propósito deste trabalho esteja centrado na análise histórica, mostrando o contexto político e social em que se estruturou o programa, a pesquisa científica também cumpre uma função social importante de buscar elementos para subsidiar a tomada de decisão - nesse caso, pelos gestores de saúde locais.

Em uma das raras publicações encontradas sobre a organização inicial do Programa DST/Aids no Amazonas, Benzaken et al. (1998, p.II.10.1) reforçam a ideia de que a resposta estadual foi marcada por estruturas de saúde bastante desarticuladas e carentes de capacidades institucionais que pudessem responder ao aumento da demanda por assistência:

a administração política do estado, mesmo contando na última década, com a dedicação de empenhados profissionais no combate à infecção pelo HIV, descontada a pouca experiência e o pioneirismo dos profissionais envolvidos, não conseguiu das autoridades sanitárias qualquer tipo de priorização do Programa DST/Aids entre as políticas de saúde pública.

Apesar da data de produção do texto, o discurso parece ainda permanecer atual. A Aids continua propondo novos desafios. Com a cronificação da doença, é preciso inovar nas estratégias de prevenção, aumentar testagem, continuar assegurando medicamento e insumos para demanda crescente, implantar rede de assistência no interior do estado. Diminuir a 
vulnerabilidade da população amazonense passa inevitavelmente por uma decisão política das autoridades de saúde do estado.

É nesse cenário de reduzida importância do programa na hierarquia das políticas de saúde, crescimento populacional, aumento das atividades econômicas em todo o estado, principalmente na capital, que o vírus segue vitorioso no seu intento de continuar existindo nas fronteiras desse vasto território.

\section{NOTAS}

${ }^{1}$ Durante sua história, a instituição passou por algumas reestruturações e mudança de razão social. Para facilitar a leitura, optamos por referir-nos a ela, a partir daqui, apenas como Alfredo da Matta ou Fuam.

${ }^{2}$ Para o serviço, foram designados os médicos Edson Sarkis e Adele Benzaken.

${ }^{3}$ Após reestruturações, a Secretaria Estadual de Saúde passou por várias denominações. Atualmente é chamada de Susam.

${ }^{4}$ Assim como a Fuam, essa instituição também passou por reestruturações e mudança de nome. Pelo mesmo motivo anterior, optamos por utilizar sempre o nome Fundação de Medicina Tropical ou FMT.

${ }^{5}$ Não foi possível levantar precisamente a data da construção do isolamento, mas as fontes apontam entre 1990 e 1994, uma vez que Tancredo Soares esteve à frente da FMT nesse período.

\section{REFERÊNCIAS}

AIDS MATA...

Aids mata, mas temos outras doenças que matam muito mais. Diário do Amazonas, Caderno Cidade, p.C3. 8 mar. 1987.

ALBUQUERQUE, Bernardino C.; CÓVAS, Jaime Araújo.

O sistema de saúde no estado do Amazonas. In: Rojas, Luísa B. Iñiguez; Toledo, Luciano Medeiros de (Org.). Espaço e doença: um olhar sobre o Amazonas. Rio de Janeiro: Fiocruz. p.II.11.1. 1998.

ALTMAN, Dennis.

Power and community: answers of the organizations and cultural to the Aids. Rio de Janeiro: Relume-Dumará. 1995.

BARATA, Rita Barradas.

Cem anos de endemias e epidemias. Ciências e Saúde Coletiva, v.5, n.2, p.333-345. 2000.

BASTOS, Francisco Inácio.

Aids na terceira década. Rio de Janeiro: Editora Fiocruz. 2006.

BENZAKEN, Adele et al.

Intervenção de base comunitária para a prevenção das DST/Aids na região amazônica, Brasil. Revista de Saúde Pública, v.41, supl.2, p.118-126. 2007.

BENZAKEN, Adele et al.

Aids no Amazonas: retrospectiva histórica e situação atual. In: Rojas, Luísa B. Iñiguez; Toledo,
Luciano Medeiros de (Org.). Espaço e doença: um olhar sobre o Amazonas. Rio de Janeiro: Fiocruz. p.II.8.1. 1998.

BRAVO, Maria Inês et al. (Org.).

Políticas públicas de DST/Aids e controle social no Estado do Rio de Janeiro: capacitando lideranças e promovendo a sustentabilidade das respostas frente à Aids. Rio de Janeiro: Associação Brasileira Interdisciplinar de Aids. 2006.

BRITO, Rosa Mendonça.

100 anos de UFAM. Manaus: EdUa. 2011.

BRITTEN, Nicky.

Entrevistas qualitativas. In: Pope, Catherine; Mays, Nicholas (Org.). Pesquisa qualitativa na atenção à saude. Porto Alegre: Artmed. 2009.

CES.

Conselho Estadual de Saúde. Resolução n.43, ad referendum. Dispõe sobre o Programa Estadual DST/Aids. (Secretaria Estadual de Saúde do Amazonas, Conselho Estadual de Saúde, Manaus). 10 jul. 2009.

CES.

Conselho Estadual de Saúde. Resolução n.53, de 16 de dezembro de 2008. Dispõe sobre a proposta de estruturação interna no Programa Estadual DST/Aids do Amazonas na Fundação de Medicina Tropical. (Secretaria Estadual de Saúde do Amazonas, Conselho Estadual de Saúde, Manaus). 16 dez. 2008. 
CES.

Conselho Estadual de Saúde. Ata da $79^{a}$ Reunião do Conselho Estadual de Saúde, em 6 de março de 2001. (Secretaria Estadual de Saúde do Amazonas, Conselho Estadual de Saúde, Manaus). 6 mar. 2001.

CES.

Conselho Estadual de Saúde. Ata da $40^{a}$ Reunião do Conselho Estadual de Saúde, em 24 de junho de 1997. (Secretaria Estadual de Saúde do Amazonas, Conselho Estadual de Saúde, Manaus). 24 jun. 1997.

CES.

Conselho Estadual de Saúde. Ata da $39^{a}$ Reunião do Conselho Estadual de Saúde, em 3 de junho de 1997. (Secretaria Estadual de Saúde do Amazonas, Conselho Estadual de Saúde, Manaus). 3 jun. 1997.

CES.

Conselho Estadual de Saúde. Ata da $34^{a}$ Reunião do Conselho Estadual de Saúde, em 10 de março de 1997. (Secretaria Estadual de Saúde do Amazonas, Conselho Estadual de Saúde, Manaus). 10 mar. 1997.

CES.

Conselho Estadual de Saúde. Ata da $3^{a}$ Reunião do Conselho Estadual de Saúde, em 21 de janeiro de 1994. (Secretaria Estadual de Saúde do Amazonas, Conselho Estadual de Saúde, Manaus). 21 jan. 1994.

CHEQUER, Pedro.

Aids vinte anos: esboço histórico para entender o Programa Brasileiro. Trabalho apresentado no 6. Congresso Brasileiro de Prevenção das DST e Aids, 2006. Belo Horizonte. 2006.

Disponível em: http://sistemas.aids.gov.br/ congressoprev2006/20_anos_do_PN.htm. Acesso em: 2 abr. 2012. 2006.

\section{CONGRESSO DESTACARÁ...}

Congresso destacará combate à Aids. Amazonas em Tempo, Terceiro Caderno, p.1. 21 fev. 1988.

FRANÇA, Martha San Juan.

Política, direitos humanos e Aids: uma conversa com Paulo Roberto Teixeira. Interface, v.12, n.27, p.919-926. 2008.

GALVÃO, Jane.

1980-2001: uma cronologia da epidemia de HIV/Aids no Brasil e no mundo. Rio de Janeiro: Associação Brasileira Interdisciplinar de Aids. 2002.

GRANGEIRO, Alexandre et al. Evaluation of strategies by Brazilian Ministry of Health to stimulate the municipal response to Aids. Cadernos de Saúde Pública, v.27, supl.1, p.s114-s128. 2011.
GRANGEIRO, Alexandre et al.

Estratégias de descentralização e municipalização da resposta à Aids no Brasil: implicações para as secretarias de saúde e organizações não governamentais. Tempus: Actas de Saúde Coletiva, v.4, n.2, p.15-34. 2010.

GRANGEIRO, Alexandre; TEIXEIRA, Paulo Roberto.

Resposta à Aids no Brasil: contribuições dos movimentos sociais e reforma sanitária. Revista Panamericana de Salud Publica, v.6, n.1, p.87-94. 2009.

GRUSKIN, Sofia; MILLS, Edward J.; TARANTOLA, Daniel.

History, principles, and practice of health and human rights. The Lancet, v.370, p.449-455. 2007.

IBGE.

Instituto Brasileiro de Geografia e Estatística. População dos municípios das capitais (população presente e residente). Disponível em: http://seriesestatisticas.ibge.gov.br/series. aspx?vcodigo $=\mathrm{CD} 79 \& \mathrm{sv}=58 \& \mathrm{t}=$ populacao-dosmunicipios-das-capitais-populacao-presente-eresidente. Acesso em: 15 jun. 2012. 2012.

MANAUS SOFRE...

Manaus sofre escassez de imóveis para alugar. A Crítica, Caderno Cidade, p.2. 4 mar. 1986.

MANN, Jonathan.

Saúde pública e direitos humanos. Physis, v.6, n.1-2, p.135-145. 1996.

MARQUES, Maria Cristina da Costa.

Saúde e poder: a emergência política da Aids/HIV no Brasil. História, Ciências, Saúde - Manguinhos, v.9, supl., p.41-65. 2002.

MS.

Ministério da Saúde. Boletim Epidemiológico Aids e DST, ano 8, n.1. Brasília: Departamento de DST, Aids e Hepatites Virais. 2012a.

MS.

Ministério da Saúde. DataSUS. Disponível em: http://www2.aids.gov.br/cgi/deftohtm.exe?tabnet/ am.def. Acesso em: 14 jul. 2012. 2012b.

MS.

Ministério da Saúde. Boletim Epidemiológico Aids, ano 14, n.2. Brasília: Coordenação Nacional de DST e Aids. 2001.

MS.

Ministério da Saúde. Relatório do Programa Nacional de DST/Aids 1992-1994. Brasília: Ministério da Saúde. 1994.

MS.

Ministério da Saúde. Relatório do Encontro

Nacional de Coordenadores Estaduais DST/Aids. Brasília: Ministério da Saúde. 1987. 
MS.

Ministério da Saúde. A Política de Incentivos. Disponível em: http://www2.aids.gov.br. Acesso em: 15 jun. 2012. s.d.

NASCIMENTO, Izaura Rodrigues.

Suframa: agência dos agentes. Somanlu: Revista de Estudos Amazônicos, ano 4, n.1, p.159-186. 2004.

PAIM, Jairnilson et al.

O sistema de saúde brasileiro: história, avanços e desafios. The Lancet, v.377, n.9779, p.1778-1797. 2011.

PEDRO TEIXEIRA...

Pedro Teixeira 25. Documentário. Direção: Marcos Tupinambá. Brasil: Up Link. 26 min. 2012.

RICCI, Antonio.

Relatório do secretário de estado de Saúde do Amazonas: gestão 1971-1974. Manaus: Secretaria Estadual de Saúde. 1974.

RIVAS, Alexandre.

O impacto da Zona Franca de Manaus no desenvolvimento do estado do Amazonas: a eficácia do modelo. Trabalho apresentado no 23. Encontro Nacional de Engenharia de Produção, 2003. Ouro Preto. 2003. Disponível em: http:// www.abepro.org.br/biblioteca/ENEGEP2003_ TR0802_0959.pdf. Acesso em: 15 jun. 2012. 2003.

RIVAS, Alexandre et al. (Org.).

Instrumentos econômicos para proteção da Amazônia: a experiência do Polo Industrial de Manaus. Curitiba: Editora CRV. 2009.

SEMSA.

Secretaria Municipal de Saúde. Versão preliminar do relatório da Oficina de Avaliação do Programa Municipal de DST/Aids nas Unidades Básicas de Saúde. Manaus: Semsa Manaus. 1998.
SEMSA.

Secretaria Municipal de Saúde. Relatório de Avaliação Controle DST/Aids na Atenção Básica. Manaus: Semsa Manaus. 1997.

SEMSA.

Secretaria Municipal de Saúde. Seção "Nossa história". Disponível em: http://semsa.manaus. am.gov.br. Acesso em: 15 jul. 2012. s.d.

SES.

Secretaria Estadual de Saúde. Plano interinstitucional de controle e prevenção das DST/ Aids no Amazonas. Manaus: SES. 1999.

SES.

Secretaria Estadual de Saúde. Instituto Alfredo da Matta ontem e hoje: história da saúde pública. Manaus: Editora IDTVAM. 1997.

SES.

Secretaria Estadual de Saúde. Ex-secretários de estado da Saúde. Disponível em: http://www. saude.am.gov.br/docs. Acesso em: 15 ago. 2012. s.d.

SERÁFICO, José; SERÁFICO, Marcelo.

A Zona Franca de Manaus e o capitalismo no Brasil. Estudos Avançados, v.19, n.54, p.99-133. 2005.

VIRGÍLIO NETO, Arthur.

Governança e instrumentos econômicos na Amazônia. In: Rivas, Alexandre et al. (Org.). Valoração e instrumentos econômicos aplicados ao meio ambiente: alternativas para proteger a Amazônia. Manaus: Instituto Piatam. p.147-152. 2008.

WORLD BANK.

Project performance assessment report: Brazil first and second Aids and STD control projects. Disponível em: http://www.worldbank.org/. Acesso em: 1 maio 2012. 2004.

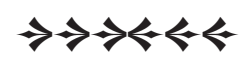

